\title{
PLAGIO CIENTÍFICO Y VULNERACIÓN DE DERECHOS FUNDAMENTALES ${ }^{1}$
}

\author{
IGNACIO FERNÁNDEZ SARASOLA \\ Profesor Titular de Derecho Constitucional \\ Universidad de Oviedo
}

\begin{abstract}
Definimos, pues, como plagio propiamente dicho, la acción de sustraer de un autor (particularmente moderno y nacional, lo cual agrava el delito) el contenido de una obra de su invención, el desarrollo de una noción nueva o mal conocida, o la aportación de uno o varios pensamientos Charles Nodier "Questions de littérature légale», 1812
\end{abstract}

SUMARIO

I. Antecedentes de hecho. II. El concepto jurídico de plagio. III. El plagio como conducta infractora de derechos fundamentales. IV. A modo de conclusión.

\section{ANTECEDENTES DE HECHO}

En los últimos meses el (por fin) exrector de la Universidad Rey Juan Carlos, Fernando Suárez, se hizo particularmente conocido por sus publicaciones. No resulta en verdad habitual que un historiador del Derecho aparezca citado casi a diario en rotativos de tirada nacional, o mencionado tanto en los informativos televisivos como en las tertulias con mayor audiencia de la radio. Pero, como a buen seguro sabe el lector, no eran las excelencias científicas del sujeto en cuestión lo que constituía un hecho noticiable, sino el copiado literal que había realizado de ideas ajenas. Durante un par de meses, casi todas las semanas salía a la luz un nuevo caso de plagio por él perpetrado²; circunstancia que ponía de manifiesto

1 Quisiera agradecer al profesor Ó. Alzaga VillaAmil el que me propusiera escribir este texto para Teoría y Realidad Constitucional.

2 La primera mención a los plagios vio la luz en el periódico «El Correo Gallego» (16-10-2016), quien realizó un seguimiento de ellos en los meses sucesivos. Especial atención prestó a la noticia el periódico 
una evidente estrategia dirigida a ampliar su currículum particular y a medrar en la vida académica sin esfuerzo y aprovechándose del trabajo de los demás.

Que cuanto escribía Fernando Suárez era una grosera copia de obras ajenas resulta evidente para cualquiera que haya superado un nivel de lectura de educación primaria: en los escritos salidos a la luz se reproducen párrafos, e incluso páginas enteras, de textos de otros autores, incluyendo, a menudo, erratas que figuraban en los originales. La mayor de las cortesías académicas del copista consistía en dejar caer una sola cita de la obra fagocitada, sin indicar en absoluto — ni tan siquiera insinuar - que todos los párrafos y páginas anteriores (obviamente sin entrecomillar) estaban literalmente calcados de ella. Tan burda estrategia quedó constatada por un informe pericial que acompañó a la denuncia interpuesta por uno de los afectados, el profesor Miguel Ángel Aparicio, donde se señalaba expresamente que el plagio era «total, literal y consciente», calificando la obra de Fernando Suárez de «usurpación clara e inequívoca».

Aquellas obras de Fernando Suárez constituyen, por tanto, una antología de escritos, un puzzle de párrafos de trabajos ajenos, pero sin indicar que en efecto de recopilaciones se trata. En otras ocasiones, la falta de honradez científica del ínclito «académico» llegaba al extremo de ni tan siquiera citar en una miserable ocasión la obra plagiada: así lo hizo, por ejemplo, con una obra de Emilio Attard (quizás pensando en su ignorancia que, al haber fallecido, sus escritos forman parte del dominio público), o de quien esto suscribe (seguramente creyendo que no soy digno de ser citado por tan excelsa lumbrera y tan altísimo cargo).

Obviamente, de quien así actúa no se puede esperar disculpa alguna, de modo que su respuesta, ante la avalancha de noticas y de críticas que le llovieron, fue pronunciarse ante su círculo de colaboradores —esto es, el Consejo de Gobierno de su Universidad— refiriéndose apenas a «disfunciones», señalando que lo copiado pertenecía al «acervo común» (lo que me permitiría a mí, por ejemplo, publicar Cien años de soledad como si fuera obra mía) y justificando que había muchas formas de citar trabajos, y que la suya (es decir copio y pego, sin más) era una de ellas ${ }^{3}$.

Más tardaron, todavía, en pronunciarse las autoridades académicas. Sólo algunas Universidades o Departamentos (como la de Alicante, o el Departamento de Derecho Constitucional de la Universidad de Barcelona) estuvieron a la altura y proporcionaron una respuesta rápida y contundente condenando los

digital eldiaro.es, merced a la espléndida labor investigadora de R. EJERIQUE. La lista de autores plagiados por F. Suárez en sus trabajos resulta interminable: L. Barbastro Gil, L. Higueruela del Pino, E. La Parra lópez, M.A. Pacheco Barrio, R. Domínguez Delgado, C. Barros...

3 El argumento fue luego reiterado por uno de los pocos universitarios que increíblemente justificaron el plagio, el profesor R. SÁnchez Domingo, de la Universidad de Burgos. En el mes de mayo de mayo, ese docente era él mismo condenado por la Sección Tercera de la Audiencia Provincial de Burgos por plagiar la obra del profesor J. C. Monje Santillana. Sentencia n 268/2017. Audiencia Provincial de Burgos. Sección 3 (17 de mayo de 2017). 
plagios y respaldando a aquellos profesores objeto de robo intelectual que pertenecían a sus instituciones. Los rectores de las Universidades madrileñas, seguramente empujados por la situación más que voluntariamente, emitieron más tarde un tibio comunicado para criticar los «presuntos plagios» aunque sin referirse expresamente al plagiario en cuestión. La CRUE — vergonzosamente silente en todo el proceso- acabó finalmente por excluir a Fernando Suárez de su comisión permanente, la Real Academia de la Historia lo suspendió de su cargo de académico correspondiente y el propio plagiario tuvo finalmente que dimitir como director del Anuario de Historia del Derecho Español. Por su parte, ni la Comunidad de Madrid — con cuyos presupuestos se paga el salario del avezado amanuense-, ni el Ministerio de Educación (de quien dependen orgánicamente la ANECA y la CNEAI) tomaron cartas en el asunto, escudándose en la autonomía universitaria.

\section{EL CONCEPTO JURÍDICO DE PLAGIO}

La conciencia de los plagios y la consolidación del término con el que designarlos se remonta en España al siglo XVIII. En 1788, Esteban Terreros recogía la voz en su Diccionario Castellano con las voces de Ciencias y Artes ${ }^{4}$, con una definición que todavía hoy reputamos válida: «Plagiar: hurtar los pensamientos ajenos para publicaros por propios». Y añadía que «el plagiar es muy villano».

En términos jurídicos, la definición de la conducta plagiaria se halla claramente reflejada en la doctrina del Tribunal Supremo: «Por plagio hay que entender, en su acepción más simplista, todo aquello que supone copiar obras ajenas en lo sustancial: se presenta más bien como una actividad material mecanizada y muy poco intelectual y menos creativa, carente de toda originalidad y de concurrencia de genio o talento humano, aunque aporte cierta manifestación de ingenio (...) las situaciones que representan plagio hay que entenderlas como las de identidad, así como las encubiertas, pero que descubren, al despojarles de los ardides y ropajes que las disfrazan, su total similitud con la obra original, produciendo un estado de apropiación y aprovechamiento de la labor creativa y esfuerzo ideario o intelectivo ajeno». (STS 10370/1995, de 28 de enero de 1995 y STS 237/1999, de 23 de febrero).

Así pues, todo plagio incluye dos aspectos que han de tenerse presentes: por una parte, entraña una sustracción de ideas y trabajo ajenos; por otra, como señala el Tribunal Supremo, se trata de una actividad en la que no existe proceso intelectual y creativo. Ambas dimensiones del plagio han de tenerse presentes para

4 G. Colón, «Reflejos cultos de plagium y plagiarius en algunas lenguas europeas», Voces, n 3, 1992, p. 16. Véase también al respecto el esclarecedor artículo del académico de la lengua y experto en el siglo XVIII P. Álvarez De Miranda «Repudio moral del plagio y del plagiario», El País (7-01-2017). 
entender correctamente la violación de derechos individuales que entraña tal conducta, ya que si la primera supone principalmente (aunque no sólo) una violación del derecho de propiedad intelectual (art. $33 \mathrm{CE}$ ), el segundo representa también una vulneración de la libertad de creación científica (art. 20.1.b CE) y, dependiendo de quién perpetre el plagio, la infracción de los principios de mérito y capacidad exigibles para el acceso a cargos públicos (art. 23.2 CE).

El aspecto más visible del plagio es, sin duda, el primero de los referidos, la apropiación indebida de una obra ajena. La particularidad de esta infracción, frente a otras apropiaciones, no reside sin embargo en el hecho de causar necesaria ni principalmente un detrimento económico en el titular de los derechos de autor, sino en difundir la obra sin reconocimiento adecuado de la autoría, violando con ello sus derechos morales (art. 14 del Real Decreto Legislativo 1/1996, de 12 de abril, por el que se aprueba el texto refundido de la Ley de Propiedad Intelectual) $)^{5}$. En este sentido, el plagio lo es por incumplir con los requisitos básicos de la cita legítima con fines educativos y de investigación científica (art. 32 LPI), única circunstancia en la que podría excusarse quien reproduce ideas ajenas. ¿Y cuándo una cita no es legítima? Una interpretación, tanto literal como sistemática, de la LPI permite responder a esta cuestión:

a.- Cuando no se cita al autor y la fuente de la que procede la obra utilizada, según refiere de forma expresa el art. 32 LPI.

b.- Cuando, aun citándose al autor y la fuente, resulte imposible una identificación clara de los fragmentos que están reproducidos de forma literal. Faltando esa identificación, resulta evidente que el texto citado conduce al error de parecer concebido por el autor del trabajo en el que se incluye la cita deficiente. Para lograr que la identificación sea inequívoca deberá utilizarse cualquier medio que permita una individualización clara de los fragmentos objeto de reproducción, como pueden ser la inclusión de comillas o la separación del párrafo citado respecto del resto del texto, con sangrados o tipografía distinta. No se trata de imponer un modo concreto de cita, sino de exigir el uso de un instrumento que, de forma razonable, permita colegir que lo allí incluido no es más que la transcripción de obra ajena. La razonabilidad, en este caso, se habrá de ponderar como se haría para mensurar cualquier límite a un derecho fundamental, puesto que a la postre, la cita supone una restricción de la propiedad intelectual.

c.- Siempre que se introduzcan leves variaciones en el texto original citado que, sin alterar su esencia y contenido, tengan por único objeto evitar el uso de comillas u otros elementos identificadores del párrafo citado, produciéndose, de esta manera, una apropiación fraudulenta del texto citado.

d.- En las ocasiones en las que, aun cuando se cumplan con los tres requisitos anteriores, la cantidad de texto citada resulte desproporcionada para los fines de la investigación. Se trataría de situaciones en las que la cita acaba por adquirir los

5 El texto se citará como LPI en lo sucesivo. 
tintes de una antología, dando lugar así a una reproducción de obra ajena sin autorización del legítimo autor. En este sentido, el art. 32 LPI señala que la cita sólo será admisible «en la medida justificada por el fin [docente o investigador] de esa incorporación». Obviamente, la transcripción de cantidades excesivas de trabajos ajenos resulta injustificada, porque el texto plagiador carecerá incluso de la condición de «investigación» debido a su falta de originalidad.

De los cuatro casos anteriores de cita ilegítima, el plagio tendría lugar cuando se incurre en cualquiera de los tres primeros. En el último, si la autoría verdadera del texto resulta indubitada, lo que se producirá es una difusión no autorizada de su obra y en puridad no podrá hablarse de plagio.

Cuestión más compleja es la de determinar qué debe entenderse por «fragmento» a la hora de determinar cuándo existe plagio por apropiación de texto ajeno. Es evidente que un párrafo, o una página, encajarían dentro de tal pero, ¿también cualquier referencia textual de menor dimensión? La respuesta, a mi modo de ver, debe abordarse desde un punto de vista tanto gramatical como funcional. Desde la primera perspectiva, al ser las oraciones unidades que expresan ideas completas, cualquier reproducción literal de ellas debe ser considerada como cita, y ha de resultar debidamente identificada, siempre, obviamente, que en la oración anide una formulación científica original. Pero, sobre todo, debe atenderse a una perspectiva funcional, es decir, a qué se pretende proteger a través de los derechos de autor. Desde este punto de vista, la guía ha de ser que el lector pueda identificar con claridad qué parte de un trabajo ha sido concebido por quien lo firma, y qué parte de él se corresponde literalmente a lo producido por otro autor. Así pues, un concepto o un término de formulación nueva y significativa - por tanto, una unidad gramatical menor a la oración- debe ser también convenientemente citado si su elaboración ha respondido a la actividad intelectual de otra persona. Sólo en aquellos casos en los que el concepto ha adquirido una autonomía propia, por resultar de uso frecuente en el ámbito científico, podría considerarse que la cita resulta innecesaria, ya que el conocimiento de la fuente forma parte de la cultura científica y, por tanto, la «audiencia probable» del escrito puede mayormente identificar cuál es la fuente de dicho concepto ${ }^{6}$.

Si la cita correctamente formulada impide que un texto se considere como plagio, la otra eximente vendría dada por el límite temporal de la propiedad intelectual. Una vez que un texto pasa a ser de dominio público no pueden ejercerse

6 Por poner un ejemplo: si un filósofo hablase de una «teoría del cierre categorial» sin citar a G. BUENO, cuando el concepto acababa de ser formulado y no había adquirido suficiente difusión, estaría dando a entender que él mismo lo había concebido, incurriendo de ese modo en una actividad plagiaria. La situación cambia, desde luego, a día de hoy, cuando es tan sobradamente conocido quién fue el autor del concepto, que éste ya forma parte de la cultura filosófica, resultando ya innecesario citarlo. La cita, de hecho, casi resultaría una tautología. Del mismo modo, y por idéntico motivo, entre los juristas resulta innecesario citar a Hans Kelsen cada vez que mencionamos la teoría pura del Derecho. El determinar cuándo un concepto ha arraigado o no en la cultura científica es algo que podrá ser fácilmente objeto de peritaje en un proceso judicial. 
acciones civiles ni penales contra aquél que lo reproduzca, incluso sin citar la fuente. Ahora bien, es preciso tener en cuenta que el plagio tiene una doble dimensión: la del autor de la obra protegida, y la del sujeto que la copia. Si bien en el caso de bienes de dominio público no hay ya titular del derecho de autor, ello no impide que la copia de un texto ajeno - a pesar de estar libre de derechos de autor - atribuyéndosela como propia, pueda y deba tener consecuencias jurídicas contra el plagiario que más adelante veremos. Porque una cosa es la distribución libre de una obra sin derechos de autor, y otra bien distinta atribuírsela como propia y obtener con esa apropiación un beneficio fraudulento. Este es, precisamente, uno de los aspectos que da identidad propia al plagio: no entraña sólo apropiarse de una obra ajena - algo que también sucede cuando se difunde la obra de otro autor sin su permiso, aunque se lo identifique - sino de hacerse pasar él mismo por el autor intelectual del objeto científico. Y, como veremos, esta particular y específica forma de apropiación indebida ha de tener un tratamiento y una respuesta específicos.

\section{EL PLAGIO COMO CONDUCTA INFRACTORA DE DERECHOS FUNDAMENTALES}

Habitualmente el plagio se concibe como una violación de la legislación sobre propiedad intelectual o, en caso de que el plagiario hubiese actuado con ánimo de lucro, como una conducta delictiva (art. 270.1 del Código Penal). Ahora bien, mi planteamiento es que el plagio afecta también a derechos fundamentales, y lo hace desde una doble perspectiva que no siempre se tiene presente: no sólo ha de pensarse en los derechos fundamentales del sujeto plagiado, sino que también es posible apreciar la violación de otros derechos — no relacionados directamente con el plagiado - cuando el sujeto que ha realizado la copia ilegítima emplea su ilícita acción para un provecho propio.

En efecto, el plagio entraña una vulneración de la propiedad intelectual y, desde esta perspectiva, afecta directamente al art. 33 CE. Ahora bien, conviene tener presente la particularidad de la conducta plagiaria, a fin de entender la infracción constitucional que en este caso se perpetra. Muchas de las violaciones de la propiedad intelectual suponen un daño económico al propietario, perceptible generalmente más como lucro cesante que como daño emergente. Así, la fotocopia no autorizada de un libro, o la reproducción de un programa informático, entrañan una disminución de las ventas y, de resultas, del beneficio del autor. Este es el motivo por lo cual la propiedad intelectual puede entrañar limitaciones sobre el ius disponiendi del propietario del bien en el que se materializa aquélla (ATC 134/1995, de 9 de mayo, FJ. 3), por ejemplo, permitiendo copias privadas de un libro, o de un DVD, pero no la venta de reproducciones del bien sujeto a propiedad intelectual. 
En el caso del plagio, sin embargo, la existencia de un lucro cesante resulta a menudo excepcional. La infracción afecta sobre todo a los derechos morales del legítimo autor y, en concreto, al derecho que le asiste a «exigir el reconocimiento de su condición de autor de la obra» (art. 14.3 LPI), porque lo que el plagio pone en entredicho es que lo difundido sea precisamente $s u$ obra.

Ahora bien, a mi modo de ver, resulta reduccionista considerar que la conducta plagiaria sólo afecta a la propiedad intelectual y por tanto, que vulnera exclusivamente el artículo $33 \mathrm{CE}$. Muy al contrario, entraña también una violación de la libertad de creación científica tutelada en el art. 20.1.b CE. Por razones sistemáticas, esta libertad se ha incluido en el mismo artículo que las libertades de expresión e información, de las que, según el Tribunal Constitucional, constituye una concreción (STC 153/1985, FJ 5; ATC 152/1993, FJ 2), aunque con las que no pueden llegar a confundirse ni identificarse. Si el contenido subjetivo de la libertad de creación científica se limitase a proteger cualquier exposición oral o escrita de los resultados de una investigación, su propia existencia como derecho autónomo respecto de la libertad de expresión resultaría vacua. A fin de cuentas, al no hallarse esta última sujeta a una dogmática funcional ${ }^{7}$, cualquier expresión (incluida la de naturaleza científica) queda amparada por el art. 20.1.a CE. Así pues, la libertad de creación científica ha de disponer de un objeto y contenidos específicos. Por lo que se refiere al primero, éste consiste en ampliar el conocimiento científico a través de una actividad intelectual o experimental, en la que puede estar presente un factor ideológico ${ }^{8}$ (particularmente en el campo de las humanidades y ciencias sociales). Ese objeto propio de la libertad de creación científica ocupa, en realidad, una posición intermedia entre las libertades de expresión e información. Como la primera, no queda exenta de juicios de valor (STC 43/2004, FJ 5), pero, igual que la segunda, ha de observar un componente de veracidad. Cierto es que, a diferencia de la libertad de información, en el caso de la libertad científica la Constitución no ha fijado un límite interno expreso (veracidad), pero resulta obvio que éste queda incorporado en la definición misma de ciencia, que es el objeto de protección constitucional: las meras opiniones infundadas y ajenas a un método inductivo o deductivo no pueden considerarse ciencia y, de resultas, son ajenas a la tutela del art. 20.1.b CE'.

En cuanto al contenido del derecho, éste se ha determinado por lo general desde una perspectiva negativa (STC 51/2008, FJ 5) — deber por parte de terceros

7 En relación con los derechos del art. 20 CE y la ausencia en ellos de una dogmática funcional véase I. Villaverde menéndez, Los derechos del público, Tecnos, Madrid, 1995 y Estado democrático e información: el derecho a ser informado y la Constitución española de 1978, Junta General del Principado de Asturias, Oviedo, 1994.

8 R. Chueca Rodríguez, «El derecho fundamental a la investigación científica», Revista electrónica del Departamento de Derecho de la Universidad de La Rioja, nº 6, 2008, pp. 9-11.

9 Por este motivo, además, el art. 20.1.b CE distingue la creación literaria y artística de la científica. Es evidente que se trata de distintos objetos de protección iusfundamental. 
de tolerar y no interferir en el proceso científico-, aunque también se le asigna una cierta dimensión positiva (libre selección del objeto y método de estudio ${ }^{10}$, y predisposición de medios para asegurar el espacio de autonomía en que consiste el derecho ${ }^{11}$ ) e incluso prestacional, derivada de su interpretación sistemática con el art. $44.2 \mathrm{CE}^{12}$.

Cuestión problemática es la referida al deslinde entre la libertad de creación científica (art. 20.1.b CE) y la propiedad intelectual (art. 33 CE) que vendría a ser, para la mayoría de los autores, el de una relación causal y de resultas temporal: la obra producida por la actividad científica es lo que protege la propiedad intelectual, de modo que no se confunde la idea a la que se ha llegado (objeto de propiedad intelectual) con la libertad previa que ha permitido obtenerla (objeto de la libertad de creación científica) ${ }^{13}$. Ahora bien, a mi modo de ver, es posible una segunda lectura que no entrañe tan tajante distinción entre la actividad científica y su resultado, porque en realidad, la una y el otro están inextricablemente unidas. Bajo este prisma, la libertad de creación científica protege tanto el proceso creativo como sus productos intelectuales ${ }^{14}$. Aun cuando la idea producida pueda estar protegida también por el derecho de propiedad intelectual (art. $33 \mathrm{CE}$ ), el proceso creativo en sí formaría parte de la libertad de creación científica (art. 20.1.b CE), porque precisamente lo que tutela la Constitución española es la «producción y creación» científica, y de resultas la actividad generatriz de la idea ${ }^{15}$.

Esta conclusión resulta capital para calificar el plagio como una infracción no sólo del art. 33 CE (de la propiedad intelectual), sino también de la libertad de

10 G. Aruego, «El derecho fundamental a la investigación científica en la Constitución española de 1978», en R. Chueca (dir.), La investigación científica como derecho fundamental, Comares, Granada, 2012, pp. 56-57.

11 R. Chueca Rodríguez, «El derecho fundamental a la investigación científica», op. cit, p. 11.

12 M. A. Ahumada Canabes, La libertad de investigación científica. Fundamentos filosóficos y configuración constitucional, Universidad Carlos III, Madrid, 2006, p. 291. El carácter prestacional del derecho fundamental, sin embargo, debería venir dado por el propio artículo 20.1.b CE, ya que integra su dimensión subjetiva. No puede hacerse depender de un principio rector de la política social y económica, ya que estos carecen de eficacia directa. Si la dimensión prestacional del derecho fundamental se hace depender de un principio rector, el resultado es que la infracción que pudiera producirse de la «interpositio legislatoris» (por ejemplo, no proporcionando la Administración Pública un servicio a los científicos que se establezca en una ley de desarrollo del art. 44.2 CE) no lo sería de un derecho fundamental (es decir, no lo sería del art. 20.1.b CE). Dicho de otro modo: si la libertad de creación científica posee un contenido prestacional, éste debe hallarse incorporado al propio derecho como parte de su dimensión subjetiva, y no ser deducible de un principio rector.

13 C. Álvarez Romero, «La Constitución española y el derecho de propiedad intelectual», Boletín de la $A N A B A D$, vol. 29, n 1, 1979, p. 74. J. J. GómEz DíEZ, «La propiedad intelectual y el artículo 20.1.b) de la Constitución española», Revista de la Facultad de Derecho de la Universidad Complutense, n 84, 1993-1994, pp. 165-190.

14 Así lo entiende también, creo que acertadamente, M.A. Ahumada Canabes, La libertad de investigación científica. Fundamentos filosóficos y configuración constitucional, op. cit., p. 317.

15 I. Villaverde MenéndeZ, «Derecho a la producción y creación literaria, artística, científica y técnica», en M. Aragón Reyes (dir.), Temas básicos de Derecho Constitucional, tomo III: Derechos Fundamentales y su protección, Civitas, Madrid, 2011, p. 207. 
producción científica (art. 20.1.b CE). Del mismo modo que una asociación que se registrase con un nombre que generase confusión con otra ya existente violaría el derecho de asociación (y no sólo la propiedad intelectual ${ }^{16}$ al dar lugar a equívocos sobre la identidad asociativa, cuando se plagia se genera un error sobre la investigación y, por tanto, se violenta el propio derecho de creación científica.

El plagiario no sólo se apropia de un bien del que no es titular (en este caso una idea), sino que su actuación entraña también una clara suplantación del investigador que originalmente ha producido esa idea. Hace suyo todo el proceso científico, el método de trabajo, la consulta de fuentes y bibliografía... en definitiva, todo el iter intelectual que ha dado lugar al producto final. Plagiar es, en definitiva, apropiarse no sólo del resultado de la investigación, que es lo que protege la propiedad intelectual, sino del proceso investigador mismo. $\mathrm{Y}$ ahí es, precisamente, donde a mi modo de ver se produce una lesión del derecho fundamental del art. 20.1.b CE. En este sentido, debe tenerse presente que el científico se identifica personalmente con su obra; ésta forma parte indisoluble de su esencia y dignidad profesional: un científico es lo que dicen sus trabajos. Plagiar significa, por tanto, atentar contra la persona misma del científico, negándole la actividad creativa que le da identidad; no le afecta sólo como propietario de un bien (en este caso una idea), sino que entraña negar su actividad creadora y, de resultas, su condición de investigador ${ }^{17}$. Es más, si el plagio se difunde con mayor profusión que el propio texto original copiado, el resultado será que el plagiario acabará reconocido en la comunidad científica como el genuino representante de esa línea de investigación a la que, en realidad, en nada ha contribuido. En consecuencia, a través de su «personalidad científica fraudulenta» puede tener acceso a proyectos de investigación, a revistas científicas o a congresos, recortando de este modo el ámbito científico del verdadero autor de la idea (que puede quedar relegado) lo cual no puede verse sino como una violación de su libertad de creación científica.

16 La idea de que cualquier producto del intelecto humano haya de reconducirse necesariamente para su tutela a la propiedad intelectual puede dar lugar a una hipertrofia del derecho fundamental del artículo 33 CE. En realidad, tal «vis expansiva» del derecho de propiedad es el resultado de una concepción netamente liberal, y de hecho no puede desconocerse que para autores como John Locke (seguido en este punto en España por Valentín de Foronda) en realidad todos los derechos serían subsumibles en el de propiedad (la libertad personal sería la propiedad del propio cuerpo, la ideológica supondría la propiedad sobre la conciencia y así sucesivamente). Del mismo modo, al subsumir hoy en día cualquier producción del intelecto en la propiedad intelectual, corremos el riesgo de vaciar parcialmente de contenido otros derechos fundamentales ligados con dicha producción.

17 Podría emplearse en este sentido lo que yo llamaría el símil del deportista. Si un atleta asume un récord o un título competitivo que no le corresponde y participa en eventos deportivos esgrimiendo esos méritos como propios, su conducta sería muy semejante a la del plagiario. El atleta fraudulento estaría asumiendo la identidad del atleta que auténticamente posee los títulos y récords, y esa apropiación no representaría un atentado contra la propiedad intelectual, sino un fraude por esgrimir méritos que no son propios. Ésa es precisamente la situación del plagio: más allá de una apropiación indebida de un concepto o una idea, se trata de la apropiación de un mérito (en este caso científico), de donde deriva que lo que se infringe va más allá de la propiedad intelectual. 
En realidad, y por esta misma circunstancia, el plagio no sólo representa una infracción de la libertad de creación científica del verdadero autor de la idea, sino que va más allá, pudiendo violentar ese mismo derecho en otros científicos. La situación sería asimilable a la que tendría lugar cuando conscientemente se propaga una noticia falsa. Dicha noticia no entrañaría ejercicio de la libertad de información (por incumplir el deber de veracidad) y viciaría el proceso destinado a formar una opinión pública libre y, de resultas, afectaría al derecho a ser informado $^{18}$. Del mismo modo, el plagio —igual que un descubrimiento científico fraudulento - distorsiona el ámbito científico (objeto de protección constitucional, igual que lo es la opinión pública), promoviendo conscientemente a error entre los miembros de la comunidad investigadora: un investigador puede citar la obra del plagiario creyendo, erróneamente, que lo que allí se incluye ha sido efectivamente producido por aquél. Esa cita quedará, de resultas, viciada y el escrito de ese investigador sufrirá un perjuicio indirecto derivado del plagio. Su libertad de creación científica habrá resultado vulnerada, porque si se incorporan de forma intencionada elementos falsos en el acervo científico (como sucede en el caso de los plagios) los miembros de la comunidad investigadora no se hallan en condiciones de ejercer su libertad.

Ahora bien, como ya he señalado, a la hora de determinar los derechos fundamentales vulnerados con una conducta plagiaria hay que atender también a la específica condición del sujeto que comete el abuso. Para ello debemos recordar que, en su definición de plagio, el Tribunal Supremo ha aclarado que en éste no existe proceso intelectual y creativo o, lo que es lo mismo, que en el plagio no hay ciencia ni tampoco actividad científica alguna, quedando obviamente desprotegido por el art. 20.1.b CE. Así pues, si el proceso creativo es requisito para el ejercicio de un derecho fundamental, el plagiario no sólo estará lesionando las libertades del verdadero autor de la idea (su propiedad intelectual y su libertad de creación científica, según hemos visto), sino que podrá incurrir, además, en una infracción constitucional adicional. La situación más evidente es la de aquel que a través de un plagio accede a un cargo público o, siendo empleado público, asciende en la carrera funcionarial. Ya que el acceso a cargos públicos ha de realizarse conforme a los requisitos de mérito y capacidad (art. 23.2 CE), y siendo así que el plagio no representa «proceso intelectual y creativo» alguno, el plagiario habría alcanzado un puesto público para el que no ha demostrado capacidad y mérito o, mejor dicho, los ha demostrado de forma fraudulenta, infringiendo así el citado art. 23.2 CE.

La situación no difiere en absoluto de lo que sucedería si por ejemplo se demostrase que en unas oposiciones un candidato ha empleado fraudulentamente un adminículo para superar unas pruebas físicas exigibles en el proceso selectivo. En

18 Al respecto, véase I. Villaverde Menéndez, Estado democrático e información: el derecho a ser informado, Junta General del Principado de Asturias, Oviedo, 1994. 
tal tesitura, no cabe duda que otorgarle el puesto vulneraría el art. 23.2 CE y que el resto de candidatos podría interponer el pertinente recurso administrativo contra el acto de adjudicación del puesto. Lo mismo sucede con el plagio: valiéndose de la muleta de trabajos ajenos, el plagiario está accediendo a empleo público o a categorías funcionariales superiores en clara infracción constitucional. El resultado es que, aparte de la obvia posibilidad de recurrir en amparo una vez agotadas las vías administrativas y judiciales, la propia Administración Pública debe proceder a la revisión de oficio de aquellos procedimientos administrativos - acreditaciones, antigüedad en el puesto, sexenios de investigación - en los que se hubiesen alegado como méritos las obras que incurren en plagio. Así se deriva del hecho de que resulten susceptibles de revisión de oficio los actos nulos (art. 106 de la Ley 39/2015, de 1 de octubre, del Procedimiento Administrativo Común de las Administraciones Públicas) y son tales, entre otros, aquellos que «lesionen los derechos y libertades susceptibles de amparo constitucional» (art. 47.a de la Ley 39/2015), como es el caso ${ }^{19}$. En el supuesto específico del profesorado universitario, la revisión de los actos administrativos le correspondería al órgano encargado de acreditar al profesorado (ANECA), a la Universidad a cuyo puesto de trabajo ha accedido el plagiario de forma fraudulenta y, en fin a la CNEAI por lo que respecta a los sexenios de investigación que le hayan sido reconocidos. No puede desconocerse que tanto la ANECA como la CNEAI son organismos autónomos y que, en cuanto tales, tienen naturaleza de Administración Pública ${ }^{20}$ y se hallan positivamente vinculados al principio de legalidad, de modo que la admisión de méritos falsos y la negativa a revisar cualesquiera reconocimientos basados en ellos conculca la obligación que tienen de evaluar de forma objetiva los requisitos de los aspirantes y su sujeción a los principios de ética profesional y responsabilidad ${ }^{21}$.

19 Resulta, pues, manifiestamente incierto - y una patética evasiva- el fundamento empleado por el Ministro de Educación para negarse a evaluar los plagios de Fernando Suárez. Según su criterio, sólo si hay infracción penal el acto es nulo y, por tanto, revisables los méritos del plagiador por la CNEAI y la ANECA. Sin embargo, lo cierto es que estos órganos no tienen por qué esperar a una sentencia penal para considerar que existe plagio; su función es valorar los «méritos y capacidad», y si contrastan, en virtud de su discrecionalidad técnica, que existen documentos falsos, están obligados por el principio de legalidad e interdicción de la arbitrariedad, así como por la vinculación positiva de la Administración Pública, a no admitir esos méritos.

20 La CNAI y la ANECA, tienen la condición de organismo autónomo (art. 43.1.a) de la Ley 6/1997, de 14 de abril, de Organización y Funcionamiento de la Administración General del Estado), hallándose adscritos al Ministerio de Educación, Cultura y Deportes a través de la Secretaría General de Universidades (art. 8 de la Ley 15/2014, de 16 de septiembre, de racionalización del Sector Público y otras medidas de reforma administrativa). Los organismos autónomos disfrutan de naturaleza de Administración Pública, de conformidad con lo dispuesto por el art. 2.2.a) de la Ley 40/2015, de 1 de octubre, de Régimen Jurídico del Sector Público. Igualmente, de conformidad con el art. 4 del Estatuto del Organismo Autónomo Agencia Nacional de Evaluación de la Calidad y Acreditación, aprobado por Real Decreto 1112/2015, de 11 de diciembre, la ANECA ejerce potestades administrativas y sus actos tienen consideración de actos administrativos (art. 28 del Real Decreto 1112/2015, de 11 de diciembre, por el que se aprueba el Estatuto del Organismo Autónomo ANECA).

21 Art. 32 de la Ley Orgánica 6/2001, de 21 de diciembre, de Universidades; art. 31 de la Ley 14/2011, de 1 de junio, de la Ciencia, la Tecnología y la Innovación; art. 6.1 del Decreto 1112/2015, de 11 de 
En términos estrictamente legales el plagio podría incluso derivar en responsabilidad penal. Por una parte, por incurrir en un delito de falsedad documental (art. 390 CP) al haber aportado como mérito, en el concurso-oposición correspondiente, documentos que inducen a error sobre su autenticidad. Aparte, claro está, de incurrir en un delito contra la propiedad intelectual (art. 270.1 CP). El ánimo de lucro en el plagio - necesario para que se aplique el tipo penal - resulta evidente desde el momento en que el plagiario aporta el documento falso con el objetivo de concurrir a una plaza, solicitar un sexenio de investigación, pedir un proyecto de investigación o participar en cualquier otra actividad objeto de financiación (ya sea pública o privada). Estas circunstancias entrañan la obtención de beneficios económicos, en forma de salario base, complementos, subvenciones o aportaciones económicas, de modo que no resulta difícil deducir que el plagiario ha perpetrado su acto con la finalidad de mejorar su situación financiera.

\section{A MODO DE CONCLUSIÓN}

A menudo se ve en la represión del plagio una cuestión exclusivamente ética y se insta a que las instituciones científicas elaboren códigos deontológicos que eviten tan vergonzosas conductas. Sin embargo, el problema es mucho más profundo, porque en realidad constituye una conducta manifiestamente ilegal. De hecho, reconducir el problema a una mera cuestión ética empaña la calificación jurídica del plagio, pues encierra la idea de que no se trata de un asunto que deba (o, lo que es peor, pueda) resolverse en sede judicial.

Aun siendo conscientes de que en realidad nos hallamos ante un problema con consecuencias jurídicas, es también habitual que el plagio se repute como una simple violación de la legislación sobre propiedad intelectual. Sin embargo, la particularidad del acto plagiario trasciende a tal violación. No se trata sólo de que se puedan producir daños económicos y morales al verdadero autor, como sucedería en una venta de material ajeno o una difusión no autorizada de obras que no son propias. Antes bien, en el plagio existe una apropiación del proceso mismo de investigación que ha dado lugar a la idea tutelada por la propiedad intelectual, una suplantación de la autoría que no sólo alcanza al producto final, sino al procedimiento a través del que fue gestado, a la metodología empleada para su obtención y a la identidad misma del científico, conformada por las investigaciones que produce. Por ello, la postura que he tratado de defender en este texto es que el plagio representa también una vulneración de la libertad de creación científica y, de resultas, de un derecho fundamental que cuenta con la máxima protección normativa, orgánica y jurisdiccional prevista en nuestra norma magna.

diciembre, por el que se aprueba el Estatuto del Organismo Autónomo ANECA. Art. 7.1 del Decreto 1112/2015, de 11 de diciembre, por el que se aprueba el Estatuto del Organismo Autónomo ANECA. 
Quizás siendo conscientes de esta circunstancia habrá una posibilidad de que se adopten medidas severas para atajar este mal, cuya permisividad avergüenza tanto a quien lo perpetra, como a quien lo permite o justifica con su silencio y connivencia.

$* * *$

TrTLE: Scientific Plagiarism and the Violation of Fundamental Rights

ABSTRACT: The article studies the scientific plagiarism, act that not only deals with intellectual property but also with the violation of fundamental rights.

Resumen: El artículo estudia el plagio científico, no sólo desde la perspectiva de la propiedad intelectual, sino también como conducta que vulnera determinados derechos fundamentales.

KEY WORDS: scientific plagiarism, intellectual property. fundamental rights.

Palabras Clave: plagio científico, propiedad intelectual, derechos fundamentales.

FECHA DE RECEPCIÓN: 16.06.2017 FECHA DE ACEPTACIÓN: 26.07.2017 
